\title{
ИМПОРТОЗАМЕЩЕНИЕ И ОТКРЫТАЯ ЭКОНОМИКА
}

\section{(c) 2019 Коростелев Степан Михайлович}

Соискатель кафедры экономики и управления предприятиями и производственными комплексами Санкт-Петербургский государственный экономический университет, Россия, Санкт-Петербург

E-mail: stepan.korostelev@gmail.com

В статье рассматриваются проблемы импортозамещения в условиях открытого рынка. Анализируются этапы импортозамещения и меры государственного регулирования, способствующие реализации эффективного экспортоориентированного импортозамещения.

Ключевые слова: импортозамещение, ориентация на экспорт, тарифное регулирование, государственное регулирование

Сама проблема импортозамещения не является новой ни для российской, ни для зарубежной научной мысли, а тем более в практическом плане. Из прошлой, начиная с Ивана Грозного [1], и новейшей российской истории можно привести ряд примеров целенаправленной замены импортной продукции на российскую. Основой этого был ряд причин, связанных как с освобождением от импортозависимости, поддержки национальной промышленности, реакцией на внешние санкции и др. Тем не менее, в современных условиях решение проблемы импортозамещения, являясь определенным следствием санкций, заключается, на наш взгляд, не в быстрейшем преодолении их последствий, а в кардинальной перестройке промышленности. СССР и Российская Федерация начиная с 1917 года практически не жили без санкций, которые существовали и во времена Российской империи. Проблема же импортозамещения возникала время от времени в результате каких-либо внешних мировых воздействий, например, падение цен на нефть что заставляло говорить о новых источниках валютных поступлений, а это становилось возможным только путем повышения конкурентоспособности ряда производств, не относящихся к нефтегазовым отраслям. К сожалению, программы импортозамещения как правило сводились к утверждению плана мероприятий, постановке определенных задач, которые как правило не выполнялись, поскольку ресурсно не поддерживались (либо ресурсы уходили «в песок»- вспомним первую кампанию конверсии, конверсионные кредиты) а сама кампания импортозамещения заканчивалась одновременно с ростом цен на энергоносители на мировом рынке.
Анализ генезиса всех кампаний по импортозамещению позволяет сказать следующее. Все государства так или иначе используют две (с различными модификациями) стратегии развития промышленности: импортозамещение и экспортоориентация. Как правило, на раннем этапе индустриализации государства происходит замена импортировавшихся ранее объектов промышленного производства на производимые в самом государстве. При этом на данном этапе, реализуется во многом так называемая (для оборудования, машин и механизмов) «отверточная» сборка, заключающаяся в сборке объекта производства из импортируемых полуфабрикатов и комплектующих. В дальнейшем, возможна локализация производства, т.е. замена ряда импортируемых полуфабрикатов и комплектующих на отечественные. Если говорить об использовании данной стратегии в России, то в настоящее время уровень локализации в автомобилестроении составляет нынешних 35-50\% но предполагается его увеличение в 2024 году до 70-75\%, что позволит лучше защититься от инфляционных процессов и скачков курсов валют, а также сделает более выгодным экспорт автокомпонентов [2].

На первом этапе стратегия замены импортируемой продукции предполагает наращивание (или начало) производства товаров потребления, не всегда нуждающихся в высоких технологиях (поскольку их просто может не быть, а получение их связано с определенными барьерами таможенными или санкционными). Упрощенно, реализация экономического роста может быть достигнута за счета замены импорта, роста экспорта и расширения внутреннего рынка. Если первые два источника непосредственно 
связаны с эффектами международной торговли, то третий - с возможными расходами бизнеса и населения внутри страны.

Итак, замена импорта товарами, произведенными национальной промышленностью, в первую очередь, производится для удовлетворения внутреннего спроса (Bruton 1998) [3]. При этом промышленность (или виды производства, или отдельные товары) нуждаются в определенной защите, которую эффективно можно реализовать только на государственном уровне. Набор инструментов защиты достаточно широк и хорошо известен в рамках государственного регулирования экономики. Это тарифы, квоты, обменный курс, цены факторов производства, процентная ставка и др. Короче говоря, формируется стратегия развития национальной промышленности на основе протекционизма, отдающая приоритет развитию местного производства. Особо следует сказать об обменном курсе: падение стоимости валюты страны приводит как правило к невыгодности импорта, его снижении и замещении отечественной продукцией, однако, в конечном итоге, это дает кратковременный эффект, приводя к отрицательному балансу внешней торговли.

Директивное регулирование цен, процентной ставки и обменного курса представляется в определенной степени репрессивным воздействием. Высокая степень защиты отечественного производителя, как было отмечено рядом зарубежных авторов, приводит к значительному разрыву между внутренними и внешними ценами. Отсутствие же конкуренции с иностранными производителями снова потребует вмешательства правительства, что, в свою очередь, негативно воздействует на экономику. Подобные протекционистские меры всегда рассматриваются как временные, поскольку предполагается, что защищаемые отрасли и виды производств разовьются до такой степени, что станут конкурентоспособными на внешних рынках. Подобная политика срабатывает не всегда, и, соответственно, появляется потребность в постоянной защите. Таким образом, стратегия импортозамещения в чистом виде ставит своей целью, в первую очередь, насыщение внутреннего рынка [4].

Подобная стратегия, может трактоваться как процесс модернизации национальной экономики, промышленности для достижения уровня развитых стран. Как отмечено выше, вначале в эту сферу вовлекаются товары потребления, а затем включается производство полуфабрикатов, целью которого является формирование технологий высокого уровня. Страна, использующая импорт полуфабрикатов и комплектующих для производства высокотехнологичной конечной продукции, рискует прийти к росту торгового дефицита, поскольку его конечная продукция пока не является конкурентоспособной на мировом рынке, а минимизация или полное устранение дефицита происходит за счет экспорта сырья и энергоносителей (при их наличии). Поскольку отечественная промышленность защищена тарифами и квотами, подобная стратегия создает препятствие для промышленных отраслей стран-экспортеров. Одним из способов преодоления подобных барьеров является перенос производства на территорию государств-импортеров, что позволяется избавится от импортных тарифов и квотирования импорта, в то время как поставка полуфабрикатов и комплектующих освобождены от этих ограничений. Таким образом, зарубежные фирмы могут преодолеть неудобства, связанные с политикой импортозамещения, производя конечную продукцию в соответствующих государствах. Тем не менее, качество этих иностранных инвестиций для страны-импортера невелико, поскольку доля добавленной стоимости производимой в стране-импортере сравнительно низка (только сборка). Вторая стадия испортозамещения предполагает две альтернативы - экспорториентированная стратегия высокотехнологичных предприятий, реализуемая при поддержке государства, и модернизация производственной структуры с целью расширения производства полуфабрикатов и комплектующих.

Тем не менее, при всей своей привлекательности, это порождает новые проблемы. Если уровень импорта полуфабрикатов и комплектующих для организации и роста сборочного производства высокотехнологичной продукции (в том числе для поставки на экспорт) превышает определенный уровень, это формирует определенный внешнеторговый дефицит, что нежелательно, для данного уровня развития. При этом данная стратегия негативно повлияет и на экспортеров. Поскольку обменный курс формируется для защиты отраслей национальной промышленности, производимые товары становятся неконкурентоспособными по цене при их экспорте. И снижение экспорта и рост 
зависимости от полуфабрикатов иностранного производства увеличивают дефицит торгового баланса, что может заставить государство прибегнуть к внешним кредитам для финансирования покрытия дефицита.

В отличии от приведенного выше, целевой задачей альтернативной стратегии является продвижение только отраслей и видов производства в промышленности, имеющих потенциал развития и конкуренции с зарубежными производителями. Главная цель стратегии состоит в том, чтобы подготовить «потенциальные» отрасли промышленности к соревнованию с зарубежными конкурентами, что возможно при их поддержке и защите на этапе возникновения и роста.

Как указано выше, большинство развивающихся стран начинали именно с развития производства на внутренний рынок с изменением впоследствии вектора деятельности на внешние рынки. Именно страны, у которых сформировался огромный внутренний рынок, используя эту стратегию, имели преимущества в темпах роста национальной промышленности, хотя пример Китая, сосредоточившегося на насыщении внутреннего рынка после некоторого провала в экспортной политики, показывает, что однозначного преимущества подобная стратегия не имеет.

Итак, государства, использующие традиционные стратегии развития промышленности, нуждаются в соответствующих структурных трансформациях, часть которых будет непо- средственно связана с управлением валютными курсами, прежде всего гибкостью обменного режима. Последнее определяет возможность управления эффективностью внешнеторгового баланса. Тем не менее, этого недостаточно. Импортозамещение не может развиваться без роста производительности труда в отраслях, ориентированных как на экспорт, так и на внутренний рынок на основе современных технологий, повышения качества человеческого капитала, изменения структуры потребляемых ресурсов и структуры их распределения. Кроме того, может использоваться политика снижения экспортных тарифов, хотя этот вид субсидии может вызвать бюджетный дефицит. Однако, тарифное регулирование, как средство защиты, более эффективно чем квотирование. Таким образом, государство, с одной стороны, сокращая или совсем ликвидируя квотирование, демонстрирует политику торговой открытости, при этом снижая уровень тарифов (какая-то конкурентная среда для определенных видов продукции должна существовать на внутреннем рынке). Именно сочетание открытости с низким курсом национальной валюты может стать эффективным способом защиты отечественного производителя. Если говорить об экспортоориентированном импортозамещении, то оно может быть успешным (во всяком случае в настоящее время для России) только через правительственную поддержку (обучение экспортеров, информационная поддержка российских экспортных товаров в зарубежных странах или прямые субсидии).

\section{Библиографический список}

1. Бочерников И.В. История антироссийских санкций: от Ивана Грозного до наших дней. https://nic-pnb.ru/ analytics/istoriya-antirossijskih-sanktsij-ot-ivana-groznogo-do-nashih-dnej/

2. Локализация, экспорт и льготы: что будет с российским автопромом. https://www.autonews.ru/news/5a9ce0 489a79473ee54ffc78?ruid=UET9A1z30Q8ExbZyA2R7Ag==

3. Bruton (1989). Import Substitution. Chapter 30, pages 1602-1644. http://faculty.nps.edu/relooney/bruton_is89. pdf

4. Sanderatne, N. (2011). Import Substitution: Is it a pragmatic economic policy? Sunday Times, Sunday November 6th, 2011. http://www.sundaytimes.lk/111106/Columns/eco.html

5. Импортозамещение в России. Википедия. https://ru.wikipedia.org/wiki/\%D0\%98\%D0\%BC\%D0\%BF\%D0\%BE\% D1\%80\%D1\%82\%D0\%BE\%D0\%B7\%D0\%B0\%D0\%BC\%D0\%B5\%D1\%89\%D0\%B5\%D0\%BD\%D0\%B8\%D0\%B5_\%D0 \%B2_\%D0\%A0\%D0\%BE\%D1\%81\%D1\%81\%D0\%B8\%D0\%B8 